\title{
Taxation, social protection, and governance decentralization
}

\author{
Gil S. Epstein ${ }^{1}$ and Ira N. Gang ${ }^{2}$
}

Addresses:

Gil S. Epstein, Department of Economics, Bar-Ilan University, Ramat-Gan 52900

Israel; phone (972) 528550 407, email: Gil.Epstein@biu.ac.il

Ira N. Gang, Department of Economics, Rutgers University, 75 Hamilton St, New Brunswick NJ 08901-1248 USA; phone (+1 848 932-8648), fax (+1 732 932-7416), email: gang@rutgers.edu

\begin{abstract}
Governments do not have perfect information regarding constituent priorities and needs. This lack of knowledge opens the door for groups to lobby in order to affect the government's taxation levels. We examine the political economy of decentralized revenue-raising authority in light of social protection expenditures by constructing a theoretical model of hierarchical contests and comparing the implications of centralized with decentralized governance. Increasing information available to the government may generate additional expenditures by interest groups trying to affect government taxation decisions. We show the potential existence of a poverty trap as a result of decentralization in taxation decisions.
\end{abstract}

Keywords: governance; decentralization; economic-models-of-political-processes; contests; rentseeking; intergovernmental-relations

JEL classification: $\mathrm{H} 77, \mathrm{D} 72, \mathrm{H} 73$

Acknowledgements: This paper builds on our previous work that has been circulated under the title 'Government and Cities: Contests and the Decentralization of Decision Making'.

\section{Highlights:}

-Study political economy of revenue-raising in light of social protection expenditures -Analyse decision-making decentralization over taxes in a rent-seeking framework -Characterize how decentralization and information changes rent-seeking and tax burden -Information may generate expenditures by those trying to affect government decisions -Poverty trap may result from hierarchical contest and decentralization in taxation 


\section{Introduction}

Many countries have a federal governmental structure consisting of a central authority and various sub-central jurisdictions. Within these sub-central jurisdictions there are other jurisdictions; and within these, still other jurisdictions, each possessing different information on their constituents. Often there is a mismatch between where the taxing authority lies and where the expenditures are made. Sometimes, the taxing authority lies with the central administration, though at least some expenditure is made by local governments, while elsewhere the reverse holds.

There is a large literature on intergovernmental decentralization. Some of this literature, including various aspects of fiscal federalism, is nicely reviewed in Gramlich (1977), Oates (1999) and Tanzi (2001). Among the topics in the intergovernmental grants literature are revenue sharing (Fisher 1979; Nitzan 1977; Zhuravskaya 2000), fiscal equalization across subnational jurisdictions (Boadway and Flatters 1982; Goodspeed 2000), fungibility and flypaper effects (Zampelli 1986; Hines and Thaler 1995), foreign aid (Cashel-Cordo and Craig 1990; Gang and Epstein 2006; Gang and Khan 1991; Heller 1975; Pack and Pack 1993; Swaroop, Jha and Rajkumar 2000), and taxation (Goodspeed 1995). Bardhan (2002) suggests that decentralization may need some protection against its own enthusiasts. In fact, the literature has frequently emphasized the difficulties that face decentralized authorities (Bardhan 2002; Bardhan and Mookherjee 2005; Fisman and Gatti 2002; Treisman 1999).

The literature on the assignment of revenue-raising instruments among levels of government is not as extensive as that on fiscal transfers or expenditures. Never-the-less it is quite compelling (Bardhan 2002; Boadway 2001). For example, Boadway, Cuff and Marchand (2003) investigate the appropriate assignment of taxes to regional governments and the accompanying set of transfers in standard fiscal federalism models. Decentralized taxation has undergone extensive theoretical consideration in traditional political economy models of governments, with bureaucrats often playing the role of Leviathan (Seabright 1996). And while the literature addresses how decentralization interacts with political institutions and incentives (Weingast 2014), it does not explicitly model the agents and the bargaining mechanisms that arise at the core of decentralized governances.

Our approach is somewhat different. We start from the presumption that the central authority does not possess all of the information necessary to best allocate its funds and raise its revenues. The central authority needs information inputs; this opens the door for it to be influenced by rentseeking activities. We ask the question: Is it better or not to have a decentralized structure with an intermediate level of government between the central authority and the local population? We think of the population organizing itself into interest or constituency groups, which we refer to as institutes. Thus, rather than examining the impact of taxation, we are interested in the impact of the competition among institutes on the assignment of revenue-raising requirements among levels of the hierarchy and the costs of additional levels of hierarchy measured against the information gains. This is close in some sense to Wärneryd (1998) who shows that a system of federalism is especially significant in ameliorating distributional competition and conflict.

To address our question we set up a theoretical model of hierarchical rent-seeking and compare the implications of centralized revenue-raising with decentralized taxation. The central authority may choose to directly tax constituent groups or it may choose to decentralize decision-making by allocating the taxation responsibilities to, for example, cities or provinces who in turn tax groups within their districts. We analyse this decentralization of decision-making in a theoretical rentseeking framework. In essence, we are comparing the outcome of a one-stage game (the central 
authority making its optimal taxation decisions with regard to the institutes) to the outcome of a two-stage game (the central authority makes its optimal taxation decisions for competing intermediate authorities which make their taxation decisions for competing institutes within their jurisdiction, see Baik and Lee 2000). We take into account the knowledge that the central and intermediate authorities have regarding each other and the institutes. We also offer insight into whether decentralization increases or decreases total rent-seeking activity, and how the level of information possessed by the central authority and the cities affects rent-seeking activity and the tax rate. Increasing the information possessed by the government may generate additional expenditures on the part of those seeking to reduce their tax obligations. We analyse the potential existence of a poverty trap as a result of decentralization.

\section{The role of the government and the information structure}

We assume that the social protection expenditures are fixed and exogenous and are met by raising tax revenues. We use the terms taxes, revenues, tax rate, tax policy and revenue-raising interchangeable as we simplify by assuming the size of the tax base is fixed (Das-Gupta and Mookherjee 1998; Das-Gupta and Gang 2005). Keeping social expenditures fixed essentially allows us to examine policies that are neutral with respect to the revenue they raise. ${ }^{1}$ Ultimately taxes are paid by the people who organize themselves into interest groups or institutes. As in Epstein and Nitzan (2002), central government politicians and bureaucrats are recipients of the lobbying efforts of cities and institutes. Lobbying efforts may be dollars directly paid to members of the central government, political and business connections, or other such relationships. Below we specify the role of the central government and its objectives more formally.

Our model has the following characteristics. There are three layers in the hierarchy. Characteristically, the top layer is the central government, the intermediate level is the state, provincial or metropolitan (city) government, and the lower level the local governments, or, possibly, the people, interest groups, organizations or institutes. Of course, we could describe many other hierarchical relations. Here we assume there is a central authority called the government. At the intermediate level, there are two cities, city A and city B. Within each city, there are the people who organize themselves into interest groups, or for brevity, institutes. Lobbying to reduce taxation goes on at the different levels. For example, the institutes may lobby their cities or the government itself.

Consider a government that has to choose which city/institute to tax more. Standard economic theory assumes that the government has utility that allows it to rank alternatives. The government then chooses the highest ranked alternative. Psychologists (e.g. Luce 1959; Tversky 1969, 1972) criticize this deterministic approach, arguing that the outcome should be viewed as a probabilistic process. Their approach is to view utility as deterministic but the choice process as probabilistic. The government does not necessarily choose the alternative that yields the highest utility; instead it has a probability of choosing each of the various possible alternatives. Along these lines, Luce (1959) proposes a model of "bounded rationality" (see also Sheshinski 2001). Luce shows that when choice probabilities satisfy a certain axiom (the choice axiom), a scale, termed utility, can be defined

\footnotetext{
${ }^{1}$ In fact, if we relax the fixed social expenditure assumption (i.e., we allow $R$ to change, say increase) it would not affect our results as everything changes proportionally. Thus the outcome of the contest is such that each unit pays a proportion of the R. Below, for example, examine equations (8) and ( $\left.8^{\prime \prime}\right)$, noting that $\left(8^{\prime}\right)$ is independent of $R$ as it is the equilibrium proportion. And so on.
} 
over alternatives such that the choice probabilities can be derived from scales (utilities) of alternatives.

Another way of looking at this is that governments are limited in the information they have and during the lobbying effort become more knowledgeable regarding the wealth of the cities/institutes. Alternatively, governments consist of people who are affected by lobbying effort for political and other reasons (see for example, Epstein and Nitzan 2002, 2003, 2007; Grossman and Helpman 1994).

Our approach is to formulate a public-policy lobbying contest. Epstein and Nitzan (2006) propose a partial micro-foundation for the public-policy contest. Under this structure the rationalization of such contest success functions (CSFs) hinge on the existence of government (politician) preferences that take into account the lobbying outlays of the interest groups, in addition to public well-being.

Consider the information the central government has regarding the economic status or wealth of the different cities and institutes. One extreme case is that the government has no information regarding the wealth of the cities and institutes. In general, however, the government possesses partial knowledge of the cities/institutes wealth. Indeed, it may well be the case that the government has full information yet creates a contest in order to receive transfers from the cities and institutes in order to increase its power. The government's information level determines the contest-success function (CSF). In the first case, the contest success function is independent of the wealth of the institutes while in the second case the contest-success function is positively related to city/institute wealth.

Denote by $w_{i}$ the economic status of institute $i$ - lower $w_{i}$ institutes should face lower taxes. $w_{i}$ also captures the cost of lobbying per unit of lobbying. Lobbying to reduce taxation is time consuming, decreasing the time allocated to productive activities. By reducing the time spent on productive activities, lobbying is costly in terms of lost income. The lower the economic status of the institute the lower the opportunity cost of lobbying and the more time spent lobbying. On the other hand, as their size increases they have greater say in setting (and reducing) their tax payments.

The probability/proportion of the tax paid by an institute is a function of the lobbying effort, the wealth of the city/institute and the level of information the government has regarding its wealth. This is captured in our contest success function. Hierarchical rent-seeking, as is present in our model, is also present in Hillman and Katz (1987). They evaluate the social losses from bribe contests that are transferred up a hierarchy. In the Hillman-Katz model, rent enters the hierarchy exogenously. In our model the value of the expected rent is endogenous, reflecting incentives to divide time between rent-seeking and productive activity. Inderst, Müller and Wärneryd (2007) on the other hand consider hierarchy as an instrument to channel activities and power. Furthermore, in the rent-seeking literature it has been established that asymmetry between the contestants reduces wasteful lobbying efforts. The asymmetry can be in terms of the lobbying capabilities, wealth endowments, attitudes toward risk or rent valuations of the contestants, as in, for example, Allard (1988), Gradstein (1994), Nitzan (1994), and Nti (1999). In a similar way in our model asymmetry affects lobbying efforts and thus the probability of receiving a share of the taxation. 


\section{Government, cities and institutions}

\subsection{Competition between cities}

The government needs to obtain a total amount of $\mathrm{R}$ funds from the different institutes via the two cities, $\mathrm{A}$ and $\mathrm{B}$. Denote by $L_{i}$ the lobbying effort of city $i$ attempting to minimize taxes paid to the government. Denote by $\operatorname{Pr}_{i}$ the proportion/probability city $i$ pays out of the total funds $R$ the government has to collect. Therefore, the expected amount this city will pay in taxes is $P r_{i} R$. Each city invests resources in order to reduce the amount of tax payed by exerting lobbying effort $L_{i}$. $\left(1-L_{i}\right)$ is the fraction of the city's resources not used up in lobbying.

The cities are risk neutral. The objective of city $i$ is to maximize its expected payoff, given by:

$$
E\left(U_{i}\right)=\left(1-L_{i}\right) v_{i}-\operatorname{Pr}_{i} R \quad \forall i=A, B
$$

where $v i$ represents the weighted average wealth of the city, $v_{i}=\sum_{j \in i} k_{j} w_{j} \quad$ for $i=A, B$ where $w_{j}$ represents the wealth or economic status of institute $j$ and $k_{i}$ represents the "weight" of that institute in the city (the weight may be a function of different variables).

The proportion/probability a city pays is a function of a number of factors. The probability/proportion $\operatorname{Pr}_{i}$ is a negative function of the lobbying effort of city $i$ and is positively affected by the lobbying effort of city $j$. Moreover, $\operatorname{Pr}_{i}$ is positively related to the wealth of city $i, v_{i}$ and negatively to the wealth of city $j, v_{j}$. As $v_{i}$ increases city $i$ is wealthier and thus will need to pay more to the government. $\operatorname{Pr}_{i}$ is also a function of the information level the government has regarding the real wealth of the cities. Denote this level by $\alpha . \alpha$ is assumed to be identical for all cities. As $\alpha$ increases the probability/proportion of funds received by the government from the city with the low $v$ decreases. Moreover, it is assumed that the (population) size of the city is also a factor determining the probability of paying taxes. The idea behind this assumption is that larger cities have more weight in effecting the decision- making of the government (the larger the size of the city the more noise it can make and the more influence it has on Election Day). We can also think about this as the relative lobbying ability of the different cities. In order to simplify, we assume that this ability is a direct function of the size of the city. We normalize the size of city B to unity. Therefore, the effect of the size of city $\mathrm{A}$ is denoted by $d$. Thus $d$ is a positive function of the size of city $A$. They lobby to decrease their tax responsibility and, as the city grows relative to the other city ( $d$ is bigger) they have more influence and will pay less taxes. To summarize these assumptions: 


$$
\frac{\partial \operatorname{Pr} o b_{i}(.)}{\partial L_{i}}<0, \frac{\partial \operatorname{Pr} o b_{i}(.)}{\partial L_{j}}>0, \frac{\partial \operatorname{Pr} o b_{i}(.)}{\partial d}<0, \frac{\partial \operatorname{Pr} o b_{j}(.)}{\partial d}>0
$$

and

$$
\frac{\partial \operatorname{Pr} o b_{i}(.)}{\partial v_{i}}>0, \frac{\partial \operatorname{Pr} o b_{i}(.)}{\partial v_{j}}<0
$$

Moreover, for $v_{i}<v_{j}$ it holds that $\frac{\partial \operatorname{Pr} o b_{i}(.)}{\partial \alpha}<0$ and $\frac{\partial \operatorname{Pr} o b_{j}(.)}{\partial \alpha}>0$.

We assume that $d$ appears as a weight on the lobbying effort. Each unit of lobbying has a larger effect in big cities than in small cities:

$$
\left.\frac{\partial \operatorname{Pr} o b_{A}\left(d L_{A}, L_{B}\right)}{\partial\left(d L_{A}\right)}\right|_{L_{b}=d L_{A}}=\left.\frac{\partial \operatorname{Pr} o b_{B}\left(L_{B}, d L_{A}\right)}{\partial L_{B}}\right|_{L_{b}=d L_{A}}
$$

This means that the function is symmetric and that there is a tradeoff between lobbying effects and the effect of the size of the city. It is also assumed that there are decreasing marginal effects of lobbying, ensuring that the second order conditions hold:

$$
\frac{\partial^{2} \operatorname{Pr} o b_{A}\left(d L_{A}, L_{B}\right)}{\partial\left(d L_{A}\right)^{2}}<0 \text { and } \frac{\partial^{2} \operatorname{Pr} o b_{B}\left(L_{B}, d L_{A}\right)}{\partial L_{B}{ }^{2}}<0 .
$$

Moreover, as $\operatorname{Pr} o b_{A}\left(d L_{A}, L_{B}\right)+\operatorname{Pr} o b_{B}\left(L_{B}, d L_{A}\right)=1$, i.e., the sum of proportions paid by the cities is 1 ; then if one increases the other will decrease, thus it holds that

$$
\frac{\partial^{2} \operatorname{Pr} o b_{A}\left(d L_{A}, L_{B}\right)}{\partial\left(d L_{A}\right) \partial L_{B}}=-\frac{\partial^{2} \operatorname{Pr} o b_{B}\left(L_{B}, d L_{A}\right)}{\partial L_{B} \partial\left(d L_{A}\right)} .
$$

The contest success function we employ is a variant of the Tullock (1980) lottery logit function. This function satisfies all the properties presented above. City A's probability/proportion of rent received versus city $B$ is given by:

$$
\operatorname{Pr}_{A}=\frac{\frac{1}{d L_{A}} \frac{1}{v_{A}}\left(v_{A}\right)^{\alpha+1}}{\frac{1}{d L_{A}} \frac{1}{v_{A}}\left(v_{A}\right)^{\alpha+1}+\frac{1}{L_{B}} \frac{1}{v_{B}}\left(v_{B}\right)^{\alpha+1}}=\frac{\frac{1}{d L_{A}} v_{A}^{\alpha}}{\frac{1}{d L_{A}} v_{A}^{\alpha}+\frac{1}{L_{B}} v_{B}^{\alpha}},
$$


where $\left(L_{i} v_{i}\right)$ is the value of lobbying and $v_{i}$ is the wealth or the level of affordance of the city.

This contest success function is a variant of the non-discrimination rule of Tullock (1980) (see also Hirshleifer 1989; Hillman and Riley 1989; and Epstein and Nitzan, 2003). The probability of winning the contest is therefore determined by: (a) The level of investment in lobbying activities, $L_{A}$ and $L_{B}$; (b) The effect of the relative size of city A, $d_{;}$(c) The wealth of the cities, $v_{A}$ and $v_{B} ;(d)$ The amount of information the government has regarding the wealth of the different cities, as discussed earlier, is $\alpha(0 \leq \alpha \leq \infty)$. The $\alpha$-value represents the government's level of information regarding the city's real wealth. As $\alpha$ increases, the government puts greater emphasis on the city's wealth. If $\alpha=0$, the government does not have any information regarding the city's wealth and, thus, utility depends only on the city's investment in lobbying activities. If $\alpha=\infty$, then the government has full information about the cities' wealth, which is exclusively used to make decisions on the division of resources.

This function also can also be seen a specific case of Luce's (Multinomial) Logit Model. ${ }^{2}$

The optimal lobbying effort

Each city maximizes its expected payoff (equation (1)). The first order condition for maximization is given by (second order conditions are satisfied):

$$
G_{i}=\frac{E\left(U_{i}\right)}{\partial L_{i}}=-v_{i}-\frac{\partial \operatorname{Pr}_{i}}{\partial L_{i}} R=0 \quad \forall i=A, B
$$

The optimal lobbying effort of both parties satisfies:

$$
-\frac{\partial \operatorname{Pr}_{A}}{\partial\left(d L_{A}\right)}=\frac{v_{A}}{d R} \quad \text { and } \quad-\frac{\partial \operatorname{Pr}_{B}}{\partial L_{B}}=\frac{v_{B}}{R}
$$

${ }^{2}$ Luce's (Multinomial) Logit Model postulates that the probability of an individual choosing a certain alternative $a$, from
the set of alternatives $S, a \in S, \operatorname{Pr}_{a}$, is given by: $\operatorname{Pr}_{a}=\frac{e^{q_{a} u(a)}}{\sum_{b \in S} e^{q_{b} u(b)}}$, where the parameter, $q_{a}$, represents the central government's preferences (discrimination between cities, or in the present context, the weight assigned to the size of the city or the lobbying abilities of the city). If $q_{b}=0$ for all $b$, then the all cities pay the same proportion of the total rent. Uncertainty increases if the government does not have full information regarding the city's real needs. In this setting, $u(a)$ is the value attributed by the government to the city's wealth. As stated above, cities invest effort in rentseeking activities (to hide or reveal both their own and their opponents' actual wealth from the government). The utility the government attributes to city $i$ is given by $u\left(v_{i}, L_{i}\right)$. Let the utility be the logarithmic function, such that $u\left(v_{i}\right.$, $\left.L_{i}\right)=\operatorname{Ln}\left(\frac{v_{i}^{\alpha}}{L_{i}}\right)$. Thus, utility decreases with the city's increased investment in lobbying activity, $L_{i}$, and in the wealth of the city, $v_{i}^{\alpha}$. 
The optimal solution is wealth over total revenue to be collected; i.e., each institutes' optimal lobbying is given by its wealth normalized by total revenue to be collected, adjusted by the $d$. Assuming an internal solution we denote the Nash equilibrium lobbying effort of both cities that solves (7) by $L_{A}{ }^{*}$ and $L_{B}{ }^{*}$.

Using (5) we obtain that the optimal lobbying efforts of the cities are given by:

$$
L_{A}^{*}=\frac{d R v_{A}^{\alpha} v_{B}^{\alpha+1}}{\left(v_{A}^{\alpha+1}+d v_{B}^{\alpha+1}\right)^{2}} \quad \text { and } \quad L_{B}^{*}=\frac{d R v_{A}^{\alpha+1} v_{B}^{\alpha}}{\left(v_{A}^{\alpha+1}+d v_{B}^{\alpha+1}\right)^{2}}
$$

Thus, we obtain that the equilibrium proportion paid by each city will equal:

$$
\operatorname{Pr}_{A}^{*}=\frac{v_{A}^{\alpha+1}}{v_{A}^{\alpha+1}+d v_{B}^{\alpha+1}} \quad \text { and } \operatorname{Pr}_{B}^{*}=\frac{d v_{B}^{\alpha+1}}{v_{A}^{\alpha+1}+d v_{B}^{\alpha+1}}
$$

and the expected payoff of each city is

$$
E\left(U_{A}^{*}\right)=R \frac{v_{A}^{1+\alpha}\left(v_{A}^{1+\alpha}+2 d v_{B}{ }^{1+\alpha}\right)}{\left(v_{A}{ }^{1+\alpha}+d v_{B}{ }^{1+\alpha}\right)^{2}} \text { and } E\left(U_{B}^{*}\right)=R \frac{v_{B}^{1+\alpha}\left(v_{B}^{1+\alpha}+2 d v_{A}{ }^{1+\alpha}\right)}{\left(v_{A}{ }^{1+\alpha}+d v_{B}{ }^{1+\alpha}\right)^{2}} \text {. }
$$

The effect of a change in the relative size of city $A$ on lobbying activities

We now consider the effect that a change in the size of $d$, the relative lobbying ability of city A, has on the lobbying effort of both cities. We have that $d$ times their wealth is the value of the city and as this increases they pay less, however the value of the wealth itself is higher. So as they are wealthier they pay more on average. It can be shown that the Nash equilibrium in the determination of the lobbying effort of the cities satisfies:

$$
\frac{\partial L^{*}{ }_{A}}{\partial d}=\frac{R v_{A}^{\alpha} v_{B}^{\alpha+1}\left(v_{A}^{\alpha+1}-d v_{B}^{\alpha+1}\right)}{\left(v_{A}^{\alpha+1}+d v_{B}^{\alpha+1}\right)^{2}} \quad \text { and } \quad \frac{\partial L_{B}^{*}}{\partial d}=\frac{R v_{B}^{\alpha} v_{A}^{\alpha+1}\left(v_{A}^{\alpha+1}-d v_{B}^{\alpha+1}\right)}{\left(v_{A}^{\alpha+1}+d v_{B}^{\alpha+1}\right)^{2}}
$$


Therefore, $\operatorname{Sign}\left(\frac{\partial L_{B}^{*}}{\partial d}\right)=\operatorname{Sign}\left(\frac{\partial L_{A}^{*}}{\partial d}\right)$. Moreover, $\operatorname{Sign}\left(\frac{\partial L_{B}{ }_{B}}{\partial d}\right)=\operatorname{Sign}\left(\frac{\partial L_{A}^{*}}{\partial d}\right)<_{<} 0$ if $\frac{v_{A}}{v_{B}}<\sqrt[(\alpha+1)]{d}$. Without loss of generality, assume that $d>1$. If $v_{A}<v_{B}$ then $\operatorname{Sign}\left(\frac{\partial L^{*}{ }_{B}}{\partial d}\right)=\operatorname{Sign}\left(\frac{\partial L_{A}^{*}}{\partial d}\right)<0$, otherwise the sign of the effect of a change in $\mathrm{d}$ is ambiguous. Thus,

Proposition 1: Assuming that city $A$ is larger than city $B$, if city $A$ 's wealth is greater than that of city $B$, then the (relatively) larger is city $A$ the less lobbying effort will be invested by both cities. However, if the wealth of city $A$ is less than that of city $B$, then the conditions stated above determine the effect the relative size of city $A$ bas on the lobbying effort of both cities.

This result states that if city A is larger than city B and A's wealth is greater, then both cities will decrease their lobbying efforts.

The effect of a change in the wealth of the cities

We now consider the effect of an increase the level of $v$ on lobbying activities.

(10) $\frac{\partial L_{A}^{*}}{\partial v_{A}}=\frac{d R v_{A}^{\alpha-1} v_{B}^{\alpha+1}\left(-v_{A}^{\alpha+1}(2+\alpha)+a d v_{B}^{\alpha+1}\right)}{\left(v_{A}^{\alpha+1}+d v_{B}^{\alpha+1}\right)^{3}}, \frac{\partial L_{A}^{*}}{\partial v_{B}}=\frac{(1+\alpha) R v_{A}^{\alpha} v_{B}^{\alpha}\left(v_{A}^{\alpha+1}-d v_{B}^{\alpha+1}\right)}{\left(v_{A}^{\alpha+1}+d v_{B}^{\alpha+1}\right)^{3}}$,

$\frac{\partial L^{*}{ }_{B}}{\partial v_{B}}=\frac{d R v_{A}^{\alpha+1} v_{B}^{\alpha 11}\left(-v_{B}^{\alpha+1}(2+\alpha)+a d v_{A}^{\alpha+1}\right)}{\left(v_{A}^{\alpha+1}+d v_{B}^{\alpha+1}\right)^{3}}$ and $\frac{\partial L^{*}{ }_{B}}{\partial v_{A}}=\frac{(1+\alpha) R v_{A}^{\alpha} v_{B}^{\alpha}\left(-v_{A}^{\alpha+1}+d v_{B}^{\alpha+1}\right)}{\left(v_{A}^{\alpha+1}+d v_{B}^{\alpha+1}\right)^{3}}$.

We obtain that if $\frac{v_{A}}{v_{B}}>\sqrt[(\alpha+1)]{\frac{\alpha d}{2+\alpha}}$ then $\frac{\partial L_{A}^{*}}{\partial v_{A}}<0$;

and if $\frac{v_{A}}{v_{B}}<\sqrt[(\alpha+1)]{\frac{2+\alpha d}{\alpha d}}$ then $\frac{\partial L_{B}^{*}}{\partial v_{B}}>0$.

Thus,

If $\sqrt[(\alpha+1)]{\frac{2+\alpha d}{\alpha d}}<\frac{v_{A}}{v_{B}}>\sqrt[(\alpha+1)]{\frac{\alpha d}{2+\alpha}}$ then $\frac{\partial L_{A}^{*}}{\partial v_{A}}<0$ and $\frac{\partial L_{B}^{*}}{\partial v_{B}}>0$.

If $\frac{v_{A}}{v_{B}}<\sqrt[(\alpha+1)]{d}$ then $\frac{\partial L_{A}^{*}}{\partial v_{B}}<0$ and $\frac{\partial L_{B}^{*}}{\partial v_{B}}<0$. 
Therefore if $\sqrt[(\alpha+1)]{\frac{2}{\alpha d}+1}>\frac{v_{A}}{v_{B}}>\sqrt[(\alpha+1)]{d}$ then $\frac{\partial L_{A}^{*}}{\partial v_{A}}<0, \frac{\partial L^{*}{ }_{B}}{\partial v_{A}}>0$ and $\frac{\partial L_{A}^{*}}{\partial v_{B}}<0$, $\frac{\partial L_{B}^{*}}{\partial v_{B}}>0$. 
In other words,

Proposition 2: If the wealth of city $A$ is sufficiently small, but not too small, then: (1) an increase in the wealth of city $A$ will decrease city $A$ 's lobbying effort and will increase city $B$ 's effort. (2) an increase in city $B$ 's wealth will decrease the effort of city $A$ and will increase city B's effort.

In other words, with the value of $d$ given and $d>1$ and if $\mathrm{A}$ is wealthier then $\mathrm{B}$, then if the wealth of city A is sufficiently small relative to that of city B, then a decrease in A's wealth will make the two cities still closer to each other in their wealth. The conditions above state what will happen to the total lobbying efforts of the cities as one has increased and the other has decreased its effort. It is not symmetric for when $A$ is a bit wealthier than $B$, when A's wealth increases it moves further away from B; but when wealth of B increases it is getting closer to A's wealth.

The effect of a change in the government's information level

Let us now consider the effect of a change in the level of information, $\alpha$, the government has regarding the cities wealth on the total lobbying effort by the cities.

The sum of lobbying effort for both cities equals,

$$
L_{A}^{*}+L_{B}^{*}=\frac{d R v_{A}^{\alpha} v_{B}^{\alpha}\left(v_{A}+v_{B}\right)}{\left(v_{A}^{\alpha+1}+d v_{B}^{\alpha+1}\right)^{2}}
$$

Therefore,

$$
\frac{\partial\left(L_{A}^{*}+L_{B}^{*}\right)}{\partial \alpha}=\frac{d R v_{A}^{\alpha} v_{B}^{\alpha}\left(v_{A}+v_{B}\right)\left(-v_{A}^{\alpha+1}+d v_{B}^{\alpha+1}\right)\left(\operatorname{Ln}\left(v_{A}\right)-\operatorname{Ln}\left(v_{B}\right)\right)}{\left(v_{A}^{\alpha+1}+d v_{B}^{\alpha+1}\right)^{3}}
$$

Without loss of generality assume $v_{A}>v_{B} \quad\left(\operatorname{Ln}\left(v_{A}\right)>\operatorname{Ln}\left(v_{B}\right)\right): \frac{\partial\left(L_{A}^{*}+L_{B}^{*}\right)}{\partial \alpha}<0$ iff $\frac{\operatorname{Ln}(d)}{\operatorname{Ln}\left(v_{A}\right)-\operatorname{Ln}\left(v_{B}\right)}-1<\alpha$.

Proposition 3: If the information level is not sufficiently high, then increasing the level of information will cause, at least one of the cities, to invest more effort in lobbying activities to offset the information the government has and to convince the government that the information it has is incorrect (this may of course lead the other city also to increase its effort). However, if the information level is sufficiently high, then the total lobbying effort will decrease as lobbying becomes less effective. 
The reason for this result is that increasing the government's information level may require more activity by one city to convince the government that the information is incorrect. This, of course, may cause the other city to also increase its lobbying effort.

\section{The effect on lobbying effort of a change in the relative size of city $A$}

We want to see how the lobbying efforts are affected by the size of the city. If one city is small and the other is big what will happen to the total lobbying effort? From (11) we obtain that a change city size, which is increasing the size of city A (or increasing $d$ ), will result in:

$\frac{\partial\left(L_{A}^{*}+L_{B}^{*}\right)}{\partial d}=-\frac{v_{A}^{\alpha+1} v_{B}^{\alpha+1}}{\left(v_{A}^{\alpha+1}+d v_{B}^{\alpha+1}\right)^{2}}<0 . d$ is thus a positive function of the size of city $A$. To summarize:

Proposition 4: As the relative size of city $A$ increases, total expenditure decreases.

\subsection{Competition inside the cities}

Let us now concentrate on the competition between the institutes within a city. City A spends in order to pay taxes at a level of $P r^{*} R$ out of the total taxes need to be payed to the (central) government at a level of $R$. Thus, the revenue that city $A$ has to obtain from its institutes is given by: $r_{A}^{*}=\operatorname{Pr}_{A}^{*} R+L_{A}^{*} v_{a}$. Namely it has to raise revenue plus it has to finance its own lobbying activities.

To simplify we assume that there are only two tax paying institutes in each city $(i=1,2)$. There is no conflict between the assumption of having two institutes in each city and that the population size of the cities may differ. The expected payoffs for the institutes are given by:

$$
E\left(u_{i}\right)=\left(1-l_{i}\right) w_{i}-g_{i} r_{A}^{*}=\left(1-l_{i}\right) w_{i}-g_{i}\left(\operatorname{Pr}_{A}^{*} R+L_{A}^{*} v_{a}\right)
$$

where $w_{i}$ is the economic status, wealth or the level of income of institute $i, l_{i}$ is the lobbying effort of the institute and $g_{i}$ is the probability/proportion that institute $i$ will pay. It is assumed that

$$
\frac{\partial g_{i}\left(l_{i}, l_{j}\right)}{\partial l_{i}}<0, \frac{\partial g_{i}\left(l_{i}, l_{j}\right)}{\partial l_{j}}>0, \frac{\partial g_{i}\left(l_{i}, l_{j}\right)}{\partial z}<0, \frac{\partial g_{i}\left(l_{i}, l_{j}\right)}{\partial z}>0
$$

\section{and}

$$
\frac{\partial g_{i}\left(l_{i}, l_{j}\right)}{\partial w_{i}}>0, \frac{\partial g_{i}\left(l_{i}, l_{j}\right)}{\partial w_{j}}<0
$$

where $z$ is the weight assigned by the city to the wealth of institute $i$. This may represent the relative size of this institute, the city's preferences or the lobbying capability of the institute. The city's 
information level regarding the wealth of the institutes are given by $\beta$. It is assumed that as the city is more informed, an increase in $\beta$, the probability is that the less well-off institute will pay less taxes. As the city has more information it will make the richer pay more and the less wealthy pay less.

Each institute maximizes its expected payoff. The first order condition for maximization is given by (second order conditions are satisfied):

$$
\frac{E\left(u_{i}\right)}{\partial l_{i}}=-w_{i}-\frac{\partial g_{i}}{\partial l_{i}} r_{A}^{*}=0 \quad \forall i=1,2
$$

where $r_{A}{ }^{*}$ represents the total tax the city needs to pay (including the efforts invested to affect the amount of tax paid) for the city.

The first order condition is satisfied when:

$$
-\frac{\partial g_{i}}{\partial l_{i}}=\frac{w_{i}}{r_{A}^{*}} \quad \forall i=1,2
$$

Given that the marginal effect of lobbying on the probability of success decreases with an increase in lobbying effort (the second order condition is satisfied), we obtain that the higher is the amount the city needs to collect the more institutes invest in lobbying effort. We can define net rent as the amount a city has to collect, including the amount the city has to pay to the government and for its lobbying efforts.

Substituting the results we obtained into the expected payment of city A (equation (8) into (1)) we obtain

$$
r_{A}^{*}=R \frac{v_{A}^{1+\alpha}\left(v_{A}^{1+\alpha}+2 d v_{B}^{1+\alpha}\right)}{\left(v_{A}{ }^{1+\alpha}+d v_{B}{ }^{1+\alpha}\right)^{2}},
$$

and,

$$
\frac{\partial r_{A}^{*}}{\partial v_{A}}>0, \quad \frac{\partial r_{A}^{*}}{\partial v_{B}}<0 \quad \text { and } \quad \frac{\partial r_{A}^{*}}{\partial d}<0
$$

Thus, the total tax and payment of city A is positively related its wealth and is negatively related to the wealth of city B, and negatively related to the size of city A $(d)$. Thus, 
Proposition 5: As city $A$ is larger relative to city $B$ (its lobbying abilities are better than those of city $B$ or the government prefers city $A$ to city $B)$ the net payment of the city $A$ decreases and the lobbying effort by the institutes in city $A$ also increases.

\section{$4 \quad$ Comparing one and two stage lobbying contests}

We now compare the lobbying efforts that are extracted and the probability that institutes with the lower economic status will pay less in taxes in the two different situations: a two and one stage contest. For clarity, we do this with an example.

Assume that the contest success function in the contest between the institutes within the city is given by (in a similar way to the contest success function presented above):

$$
g_{i}=\left\{\begin{array}{l}
\frac{\left(\frac{1}{z_{A} l_{i}}\right) w_{i}^{\beta_{A}}}{\left(\frac{1}{z_{A} l_{i}}\right) w_{i}^{\beta_{A}}+\left(\frac{1}{l_{j}}\right) w_{j}^{\beta_{A}}} \text { for } i \neq j, i, j=1,2 \\
\frac{\left(\frac{1}{z_{B} l_{i}}\right) w_{i}^{\beta_{B}}}{\left(\frac{1}{z_{B} l_{i}}\right) w_{i}^{\beta_{B}}+\left(\frac{1}{l_{j}}\right) w_{j}^{\beta_{B}}} \text { for } i \neq j, i, j=3,4
\end{array}\right.
$$

If we calculate the total expenditure of both institutes in each city, we obtain in a similar way to (11),

$$
l_{1}^{*}+l_{2}^{*}=\frac{z_{A} r_{A}^{*} w_{1}^{\beta_{A}} w_{2}^{\beta_{A}}\left(w_{1}+w_{2}\right)}{\left(w_{1}^{\beta_{A}+1}+z_{A} w_{2}^{\beta_{A}+1}\right)^{2}} \text { and } l_{3}^{*}+l_{4}^{*}=\frac{z_{B} r_{B}{ }^{*} w_{3}^{\beta_{B}} w_{4}^{\beta_{B}}\left(w_{3}+w_{4}\right)}{\left(w_{3}^{\beta_{B}+1}+z_{B} w_{4}^{\beta_{B}+1}\right)^{2}} \text {. }
$$

In order to understand the results consider the following case:

1. Both cities have the same population size and have the same lobbying abilities: $d=1$,

2. Cities have no preferences regarding the division of the rents between the institutes and all institutes have the same lobbying capabilities $\gtrless_{A}=z_{B}=1$,

3. Institutes 2,3 and 4 have the same wealth denoted by $w\left(w_{2}=w_{3}=w_{4}=w\right)$ and institute number 1 's wealth is half as much as the others: $w_{1}=0.5 w$, 
4. The weighted wealth of a city is the sum of the wealth of the institutes: $v_{A}=w_{1}+w_{2}$ and $v_{B}=w_{3}+w_{4}$,

5. The information level of the cities and the government are the same and equal to 1: $\alpha=\beta_{A}=\beta_{B}=1$. It is also in (19) and (200 above as it should be.

In this situation, we can calculate the total investment in lobbying effort in both stages by all four institutes and both cities and the expected payoff of worst-off institute (number 1).

\subsection{A two-stage contest}

In the two stage contest, the cities compete first against each other regarding how much of the taxes to pay and then the institutes compete against one another. The city collects from the institutes the tax it has to pay the government plus the cost of the city's rent-seeking activity. Using (11) and (20) we obtain the following:

City A: $\quad$ Total lobbying effort would be $L_{A}=\frac{0.1536}{w} R$;

$$
\text { Payoff: } E\left(U_{A}\right)=\left(1-L_{A}\right) 1.5 w-\operatorname{Pr}_{A} R=1.5 w-0.5904 R \text {. }
$$

Thus, the city will have to collect from the institutes in the city $r_{A}=0.5904 R$.

City B:

Total lobbying effort would be $L_{B}=\frac{0.1151}{w} R_{A}$;

Payoff: $E\left(U_{B}\right)=\left(1-L_{B}\right) 2 w-\operatorname{Pr}_{B} R=2 w-0.8705 R$.

Thus, the city will have to collect from the institutes in the city $r_{B}=0.8705 R$.

Institute 1: $\quad$ Total lobbying effort would be $L_{1}=\frac{0.32}{w} r_{A}$;

Payoff: $E\left(U_{1}\right)=\left(1-L_{1}\right) 0.5 w-\operatorname{Pr}_{1} r_{A}=0.5 w-0.2125 R$.

Institute 2:

Total lobbying effort would be $L_{2}=\frac{0.16}{w} r_{A}$;

Payoff: $E\left(U_{2}\right)=\left(1-L_{2}\right) w-\operatorname{Pr}_{2} r_{A}=w-0.56678 R$.

Institutes 3 and 4: $\quad$ Total lobbying effort would be $L_{3}=L_{4}=\frac{0.25}{w} r_{B}$;

Payoff: $E\left(U_{3}\right)=E\left(U_{4}\right)=\left(1-L_{3}\right) w-\operatorname{Pr}_{3} r_{B}=w-0.6529 R$.

The total expenditure of all four institutes:

Total funds paid ${ }_{t w o}=2.08608 R$. 
Thus to pay $\mathrm{R}$ taxes the government the institutes paid more than $100 \%$ because of the lobbying.

\subsection{A one-stage contest}

Now let us consider the case where all four institutes lobby directly the (central) government in a one-stage game. We assume that the contest success function is given by:

$$
f_{1}=\frac{\left(\frac{1}{x_{1}}\right) w_{1}{ }^{\beta}}{\left(\frac{1}{x_{1}}\right) w_{1}{ }^{\beta}+x\left(\frac{1}{x_{2}}\right) w_{2}{ }^{\beta}+\left(\frac{1}{x_{3}}\right) w_{3}{ }^{\beta}+\left(\frac{1}{x_{4}}\right) w_{4}{ }^{\beta}}
$$

and in a symmetric way the probability of the other three institutes are calculated. This function satisfies the general properties presented above.

Each institute maximizes its expected payoff. The first order condition for maximization is given by:

$$
\frac{E\left(u_{i}\right)}{\partial l_{i}}=-w_{i}+\frac{\partial f_{i}}{\partial l_{i}} R=0 \quad \forall i=1,2,3,4 .
$$

Institute 1: $\quad$ Total lobbying effort would be $L_{1}=\frac{0.169884}{w} R$;

$$
\text { Payoff: } E\left(U_{1}\right)=\left(1-L_{1}\right) 0.5 w-\operatorname{Pr}_{1} R_{A}=0.5 w-0.161842 R \text {. }
$$

Institutes 2, 3 and 4: $\quad$ Total lobbying effort would be $L_{2}=L_{3}=L_{4}=\frac{0.105416}{w} R$;

$$
\begin{aligned}
& \text { Payoff: } \\
& E\left(U_{2}\right)=E\left(U_{3}\right)=E\left(U_{4}\right)=\left(1-L_{3}\right) w-\operatorname{Pr}_{3} R=w-0.413016 R .
\end{aligned}
$$

The total expenditure of all four institutes:

Total funds paid ${ }_{\text {one }}=1.401 R$. 
Thus to pay $R$ taxes to the government the institutes paid $40 \%$ more as a result of lobbying. This gives us,

Proposition 6: Under this example, total expenditure of the institutes is higher in the two-stage contest rather than in the one-stage contest. The expected payoff of all the institutes is lower under the one stage than under the two stage contests. If the government's objective is to help the worst-off institute as much as possible and to minimize wasted resources on lobbying, then a one-stage contest is optimal.

\subsection{Information aspects in a two-stage contest verses a one-stage contest}

One more critical aspect that must be considered when comparing a one-stage contest to a twostage contest is the information level the government has verses the information the city has regarding the economic status of the institutes. It is reasonable to assume that the city has more information than the government. Increasing information increases the probability that the correct (richer) institute pays more taxes. However, increasing information may increase the total wasted resources invested in lobbying activities. A two-stage contest has the advantage that after the city knows how much taxes it has to pay, it allocates the colleting correctly with a higher probability than in a one-stage contest. However, the taxes the institute has to pay may be higher than they had to as the government lacks of information regarding the actual wealth of the city.

\subsection{Poverty trap}

Assume that cities have more information than the central government. Increasing information increases the probability that the correct institute pays the correct resources. A two-stage contest has the advantage that the province with the neediest institutes receives resources from the government. After the province receives the resources it can allocate the resources correctly with a higher probability than in a one-stage contest.

Let us now consider the relationship between the city's payoff and the wealth of the institutes. From (1), the expected payoff of city $i$ in equilibrium is given by

$$
E\left(U_{i}^{*}\right)=\left(1-L_{i}^{*}\right) v_{i}-\operatorname{Pr}_{i}^{*} R
$$

Consider the case of city A where we normalize $v_{B}$ to unity and $\alpha=1$ :

$$
E\left(U_{A}^{*}\right)=\left(1-L_{A}^{*}\right) v_{A}-\operatorname{Pr}_{A}^{*} R=\frac{v_{A}^{5}+2 v_{A}^{3} d+\left(v_{A}+R\right) d^{2}}{\left(v_{A}^{2}+d\right)^{2}}
$$

Consider the effect a change in $v_{i}$ has on the equilibrium expected payoff: 


$$
\frac{\partial E\left(U_{A}^{*}\right)}{\partial v_{A}}=\frac{v_{A}^{6}+3 v_{A}^{4} d+3 v_{A}^{2} d^{2}+d^{3}-4 v_{A} d^{2} R}{\left(v_{A}{ }^{2}+d\right)^{2}}
$$

Trying to find a solution for this first order condition is not straightforward. We look at the second order condition and its sign:

$$
\frac{\partial^{2} E\left(U_{A}^{*}\right)}{\partial v_{A}^{2}}=\frac{4\left(5 v_{A}^{2}-d\right) d^{2} R}{\left(v_{A}^{2}+d\right)^{4}}
$$

If $5 v_{A}{ }^{2}>d$, then the expected payoff is $U$ shaped and if $5 v_{A}{ }^{2}<d$ the expected payoff has an inverse $\mathrm{U}$ shape. We illustrate this result using figure 1 in the following way: if the wealth of city A is sufficiently low, $v_{A}<v_{A 1}$, then the city prefers to be wealthier, $\left(\left.\frac{\partial E\left(U^{*}{ }_{A}\right)}{\partial v_{A}}\right|_{v_{A}<v_{A 1}}>0\right)$; however, if the wealth of city A is not sufficiently low or sufficiently high (not too poor or too rich), $v_{A 2}>v_{A}>v_{A 1}$, the city gains from reducing its wealth level as the decrease in wealth would be smaller than the decrease in taxes paid to the government, $\left(\left.\frac{\partial E\left(U^{*}{ }_{A}\right)}{\partial v_{A}}\right|_{v_{A 2}>v_{A}>v_{A 1}}<0\right)$. If the city's wealth is sufficiently high, $v_{A 2}<v_{A}$, its gains from the lobbying activities are low and the city prefers to be wealthier.

If the wealth of city $\mathrm{A}$ is not sufficiently low or sufficiently high, $v_{A 2}>v_{A}>v_{A 1}$, it is optimal for the city to decrease its wealth in order to increase the expected payoff (moving to wealth level $v_{\mathrm{A} 1}$ in figure 1). Thus the city pays less tax and by that increasing its expected payoff.

The idea behind this result is that if the city is not wealthy it is beneficial for it to become worseoff which in turn increases the probability of its paying less tax (see Konrad, 1994, for a similar result in the case of the provision of public goods). The question is therefore: how can a city become worse-off or at least sustain its low income position? Becoming worse-off is easier than becoming economically better-off. Let us remember that the government and the cities do not have the same level of information. The cities are assumed to have more information regarding the wealth of the institutes than the government. Thus, the city can impose more taxes on the institutes that are the worse-off ones, sustaining the low levels of the worse-off institutes. The city thus may be able to sustain low education and income levels of the average population. The lobbying system has therefore developed a poverty trap under which once you are in the trap the city would not wish to exit it. We may summarize this result in the following way

Proposition 7: If the wealth of city $A$ is not sufficiently low or sufficiently high, the city prefers to impose the tax it has to collect for the government in a way that keeps its population poor rather than allocating taxes in a way that increases its population's wealth. 
Figure 1: A Possible poverty trap

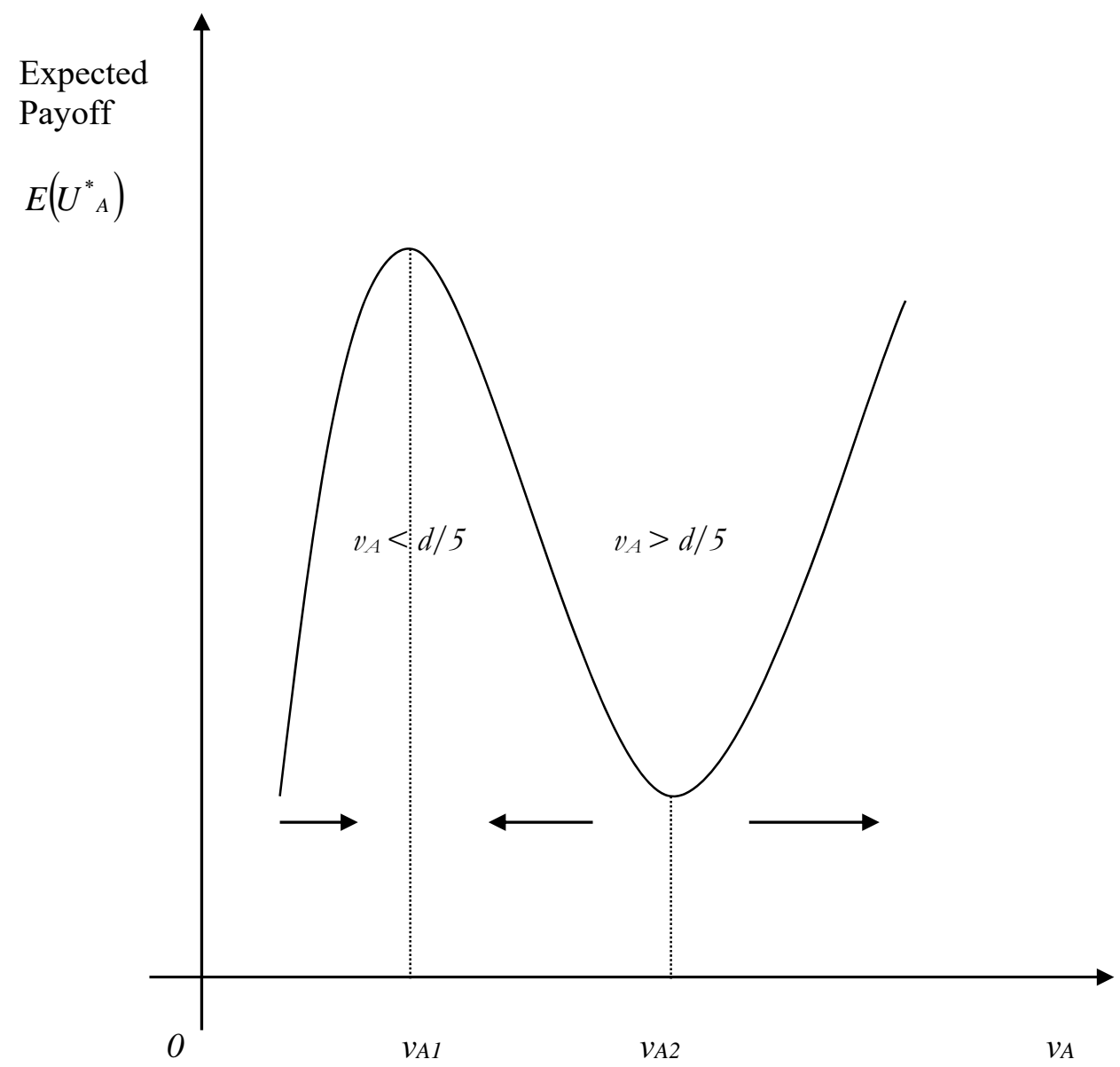

The economic status of city A

Source: Authors' illustration based example in the text. 


\section{Conclusion}

Governments do not have perfect information regarding the priorities and the wealth of different groups in the economy. This lack of knowledge opens the door for different groups to lobby the government in order to pay lower taxes. Such lobbying can be seen as rent-seeking activities attempts by different groups pay less tax. Thus, it is not clear that the tax burden will be allocated properly according to the wealthiest groups in the economy. Rather, greater taxes may be imposed on those that are not efficient rent-seekers. For example, the wealthier groups may have greater influence on the decision makers causing the government to impose the tax on others or give those with influence greater tax reductions.

If the tax burden is allocated to the non-efficient rent-seekers or those who invest relatively less effort and resources in rent-seeking activities, there are two efficiency losses: (a) the worst-off may be those that have the highest tax burden and (b) a high rent dissipation, investment of effort and resources in rent-seeking activities, decreases the resources allocated to real production and thus decreases output. In an attempt to increase efficiency, the central government may decentralize decision-making by allocating the tax gathering to different cities. The cities, in turn, will allocate obtain the tax revenue from the different groups within its district.

We analyse this decentralization of decision-making in a theoretical rent-seeking framework. We take into account the knowledge that the government has regarding the wealth of the different groups and the information the city has regarding these groups. We also provide some insight into the question of how decentralization increases or decreases total rent-seeking activity, and how the level of information possessed by the government and the cities affects rent-seeking activity and burden of taxes payed.

A consequence of the lack of information and hierarchical contests may be the development of a poverty trap. In order to pay lower taxes based on low economic status, a city may deliberately construct its policies such that the worst-off cannot become better off. Thus, in a lobbying contest, incentives may work in non-obvious ways. ${ }^{3}$ The cities have more information and can use this towards the government. If the government and the cities had the same objective, decentralization would be better. However, the cities want to pay lower taxes, causing the problem and giving rise to the trap. This is what others are missing. In brief, the city can impose greater taxes on the institutes that are the worse-off ones, sustaining the low levels of the worse-off institutes. The city thus may be able to sustain low education and income levels of the average population. The lobbying system has therefore developed a poverty trap under which once you are in the trap the city would not wish you to exit it.

While our model is of general interest for many intergovernmental structures, we concentrate in this paper on a central government authority, intermediate authorities (cities) inside that central government's authority, and interest groups, institutes or organizations within the cities representing the "people" who are the targeted beneficiaries of social expenditure policy and ultimately the source of the revenue needed to fund the programmes. We assume here that the goal of the government is to determine optimal taxation levels. Its problem is how to best structure its tax collection. We show the role information plays in the taxation determination and the potential existence of a poverty trap as a result of decentralization in taxation decisions.

\footnotetext{
3 This does not in general have to do with decentralization. However, the city can affect its wealth and thus with decentralization if can use it against the government. Without decentralization it would be harder to accomplish.
} 
Our model is one of hierarchical rent-seeking in which the fixed social expenditure bill must be met by tax revenue which ultimately is the responsibility of the central government. We compare a one-stage game in which the central government directly sets the revenue due it from each local interest group (representing the people) to a two-stage game in which the central government sets the rent due it from the cities and the cities do likewise for competing interest groups in their jurisdictions. All the actors spend funds to reduce their revenue obligations. The authorities do not know exactly the wealth of each group, but the intermediate authorities (cities) have more information than the central government, so more layers means more information. The richer your interest group (institute) the more taxes you may need to pay, so you will fight to convince the tax administrators that you need to pay less.

\section{References}

Allard, R.J. (1998). 'Rent-Seeking with Non-Identical Players'. Public Choice, 57(1): 3-14.

Baik, K.H., and S. Lee (2000). 'Two-Stage Rent-Seeking Contests with Carryovers'. Public Choice, 103(3-4): 285-96.

Bardhan, P. (2002). 'Decentralization of Governance and Development'. Journal of Economic Perspectives, 16(4): 185-205.

Bardhan, P., and D. Mookherjee (2005). 'Decentralizing Anti-Poverty Program Delivery in Developing Countries', Journal of Public Economics, 89(4): 675-704.

Boadway, R. (2001). 'Inter-governmental Fiscal Relations: the Facilitator of Fiscal Decentralization'. Constitutional Political Economy, 12(2): 93-121.

Boadway, R., and F. Flatters (1982). 'Efficiency and Equalization Payments in a Federal System of Government: a Synthesis and Extension of Recent Results'. Canadian Journal of Economics, 15(4): 613-33.

Boadway, R., K. Cuff, and M. Marchand (2003). 'Equalization and the Decentralization of Revenue-Raising in a Federation'. Journal of Public Economic Theory, 5(2): 201-28.

Cashel-Cordo, P., and S.G. Craig (1990). 'Public Sector Impact of International Resource Transfers'. Journal of Development Economics, 32(1): 17-42.

Das-Gupta, A., and D. Mookherjee (1998). Incentives and Institutional Reform in Tax Enforcement: An Analysis of Developing Country Experience. Delhi: Oxford University Press.

Das-Gupta, A., and I.N. Gang (2005). 'Decomposing Revenue Effects of Tax Evasion and Tax Structure Changes'. International Tax and Public Finance, 7(2): 177-94.

Epstein, G.S., and I.N. Gang (2002). 'Government and Cities: Contests and the Decentralization of Decision Making?’. IZA Discussion Paper 547. Bonn: IZA.

Epstein, G.S., and S. Nitzan (2002). Endogenous Public Policy, Politicization and Welfare. Journal of Public Economic Theory, 4(4): 661-77.

Epstein, G.S., and S. Nitzan (2003). 'Political Culture and Monopoly Price Determination'. Social Choice and Welfare, 21(1): 1-19.

Epstein, G.S., and S. Nitzan (2006). 'The Politics of Randomness', Social Choice and Welfare, 27(2): 423-33.

Epstein, G.S., and S. Nitzan (2007). Endogenous Public Policy and Contests. Berlin: Springer-Verlag. 
Fisher, R.C. (1979). 'A Theoretical View of Revenue Sharing Grants'. National Tax Journal, 32(2): 173- 84.

Fisman, R., and R. Gatti (2002). 'Decentralization and Corruption: Evidence Across Countries'. Journal of Public Economics, 83, 325-45.

Gang, I.N. and H.A. Khan (1991). 'Foreign Aid, Taxes and Public Investment'. Journal of Development Economics, 34(1-2): 355-69.

Gang, I.N. and G.S. Epstein (2006). 'Contests, NGOs and Decentralizing Aid'. Review of Development Economics, 10(2): 285-96.

Goodspeed, T.J. (1995). 'Local Income Taxation: An Externality, Pigouvian Solution, and Public Policies'. Regional Science and Urban Economics, 25(3): 279-96.

Goodspeed, T.J. (2000). 'Tax Structure in a Federation'. Journal of Public Economic, 75(3): 493-506.

Gradstein, M. (1994). 'Efficient Provision of a Discrete Public Good'. International Economic Review, 35 (4): 877-97.

Gramlich, E. (1977). 'Intergovernmental Grants: A Review of the Empirical Literature'. in Wallace Oates, ed., The Political Economy of Fiscal Federalism. Lexington, MA: Heath-Lexington, 219-39.

Grossman, G.M. and E. Helpman (1994). 'Protection for Sale'. American Economic Review, 84(4): 833-50.

Heller, P.S. (1975). 'A Model of Public Fiscal Behavior in Developing Countries: Aid, Investment and Taxation'. American Economic Review, 65(3): 429-45.

Hillman, A.L., and E. Katz (1987). 'Hierarchical Structure and the Social Costs of Bribes and Transfers'. Journal of Public Economics, 34(2): 129-42.

Hillman, A.L., and J.G. Riley (1989). 'Politically Contestable Rents and Transfers'. Economics and Politics, 1(1): 17-39.

Hines, J.R., Jr., and R.H. Thaler (1995). 'Anomalies: The Flypaper Effect'. Journal of Economic Perspectives, 9(4): 217-26.

Hirshleifer, J. (1989). 'Conflict and Rent-seeking Success functions: Ratio vs. Difference Model of Relative Success’. Public Choice, 63(2): 101-12.

Inderst, R., H.M. Müller, and K. Wärneryd (2007). 'Distributional Conflict in Organizations'. European Economic Review, 51(2): 385-402.

Konrad, K.A. (1994). 'The Strategic Advantage of Being Poor: Private and Public Provision of Public Goods'. Economica, 61(241): 79-92.

Luce, R.D. (1959) Individual Choice Behavior: A Theoretical Analysis (New York: Wiley).

Nitzan, S. (1977). 'Revenue Sharing in Multiperson Public Choice Models'. Quarterly Journal of Economics, 91(2): 315-26.

Nitzan, S. (1994). 'Modelling Rent-Seeking Contests'. European Journal of Political Economy, 10(1): 4160.

Nti, K.O. (1999). 'Rent-Seeking with Asymmetric Valuations'. Public Choice, 98(3-4): 415-30.

Oates, W.E. (1999). 'An Essay on Fiscal Federalism'. Journal of Economic Literature, 37(3): 1120-49.

Pack, H., and J.R. Pack (1993). 'Foreign Aid and the Question of Fungibility'. Review of Economics and Statistics, 75(2): 258-65. 
Seabright, P. (1996). 'Accountability and Decentralisation in Government: An Incomplete Contracts Model'. European Economic Review, 40(1): 61-89.

Sheshinski, E. (2001). 'Bounded Rationality and Social Optimal Limits on Choice: An Example'. Manuscript. Jerusalem: Hebrew University.

Swaroop, V., S. Jha, and A.S. Rajkumar (2000). 'Fiscal Effects of Foreign Aid in a Federal System of Governance: The Case of India'. Journal of Public Economics, 77(3): 307-30.

Tanzi, V. (2001). Pitfalls on the Road to Fiscal Decentralization. Washington, DC: Carnegie Endowment for International Peace.

Treisman, D. (1999). 'Political Decentralization and Economic Reform: A Game-Theoretic Analysis', American Journal of Political Science, 43(2): 488-517.

Tullock, G. (1980). 'Efficient Rent-seeking' in J.M. Buchanan, R.D. Tollison, and G. Tullock (eds), Toward a Theory of the Rent-seeking Society (College Station, Texas: A\&T Press).

Tversky, A. (1969). 'Intransitivity and Preferences'. Psychological Review, 76(1): 31-48.

Tversky, A. (1972). 'Elimination by Aspects: A Theory of Choice'. Psychological Review, 79(4): 28199.

Wärneryd, K. (1998). 'Distributional Conflict and Jurisdictional Organization,' Journal of Public Economics, 69(3): 435-50.

Weingast, B.R. (2014). 'Second Generation Fiscal Federalism: Political Aspects of Decentralization and Economic Development,' World Development, 53: 14-25.

Zampelli, E.M. (1986). 'Resource Fungibility, the Flypaper Effect, and the Expenditure Impact of Grants-in-Aid'. Review of Economics and Statistics, 68(1): 33-40.

Zhuravskaya, E.V. (2000). 'Incentives to Provide Local Public Goods: Fiscal Federalism, Russian Style'. Journal of Public Economics, 76(3): 337-68. 